\title{
Infant developmental profile of Crisponi syndrome due to compound heterozygosity for CRLF1 deletion
} Ingrid Anne Mandy Schierz ${ }^{a}$, Gregorio Serra ${ }^{a}$, Vincenzo Antona
Ivana ${ }^{a}$,

\section{Clinical Dysmorphology 2020, XXX:000-000}

${ }^{\text {a}}$ Department of Health Promotion Sciences, Maternal and Infant Care, Internal Medicine and Medical Specialties 'G. D'Alessandro', University of Palermo,

Via Alfonso Giordano n. 3, Palermo and 'Institute of Genetic and Biomedical

\author{
List of key features \\ Cold-induced sweating syndrome 1 \\ Camptodactyly \\ Thin corpus callosum \\ Hyperekplexia \\ Feeding difficulties \\ Periodic fever
}

\section{Summary}

A 37-week gestation infant with fetal growth restriction weighing $2400 \mathrm{~g}$ (8th centile) who was the first-born child to nonconsanguineous Sicilian parents was referred to our institution on 23rd day of life for feeding difficulties, vomiting, and apnea requiring noninvasive ventilation and oxygen supply.

On physical examination, he showed a distinctive facial appearance (Fig. 1), right head tilting caused by left sternocleidomastoid muscle hematoma, bilateral camp-

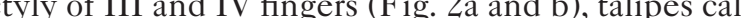
caneovalgus, mild central-type hypotonia and decreased spontaneous motricity. Gavage feeding was required for absent sucking, swallowing, and neck muscle contracture after minimal orofacial stimuli. His father had suffered from mild feeding problems during infancy and now continues to have paradoxical sweating.

At 2 months of age, he showed intermittent hyperthermia and brain MRI showed a thin corpus callosum (Fig. 3). One month later, a sleep EEG showed normal spindles maturation; a gastrostomy was performed for persisting feeding difficulties. At 5 months old, he was discharged with intermittent hyperthermia, improved muscular tone and resolution of trismus. Nevertheless, he showed developmental delay involving fine motor skills and balance reactions. At 11 months, the gastrostomy was removed. At 12 months, he weighed $9 \mathrm{~kg}$ (25th centile), was able to walk, had mild kyphoscoliosis and normal hearing. Improved manipulative skills were acquired after individualized physiotherapy (Fig. 2c-h).
Correspondence to Ingrid Anne Mandy Schierz, MD, Department of Health Promotion Sciences, Maternal and Infant Care, Internal Medicine and Medical Specialties 'G. D'Alessandro', University of Palermo, Via Alfonso Giordano n. 3, 90127 Palermo, Italy

Tel: +390916555456; e-mail: inschier@tin.it

Received 19 April 2019 Accepted 6 April 2020

\section{Investigations}

We ruled out trisomy 18 by karyotyping, and mevalonic aciduria (MEVA) by molecular analysis of mevalonate kinase gene, and we hypothesized that he may have

Fig. 1

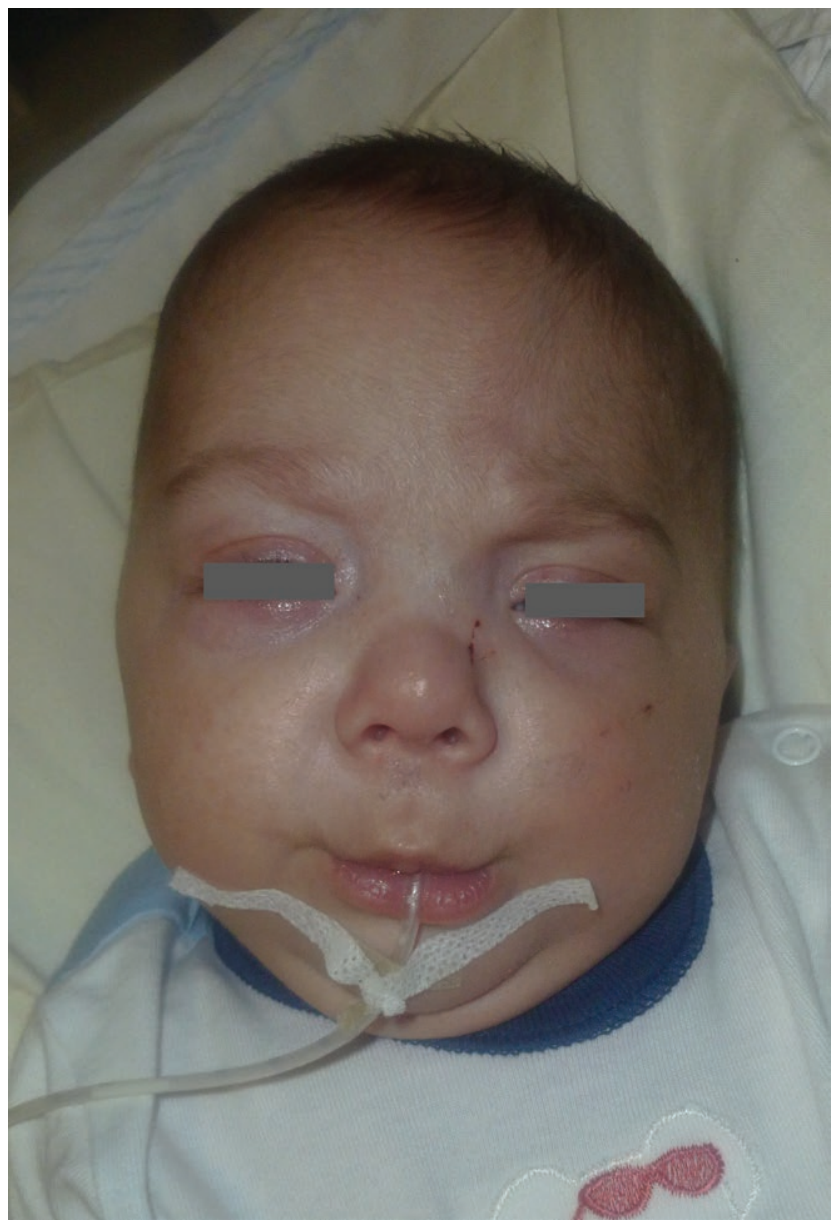

Frontal facial picture shows low-set ears, epicanthus, broad nose, anteverted nostrils, thin and pursed lips, long philtrum and micrognathia. 
Fig. 2

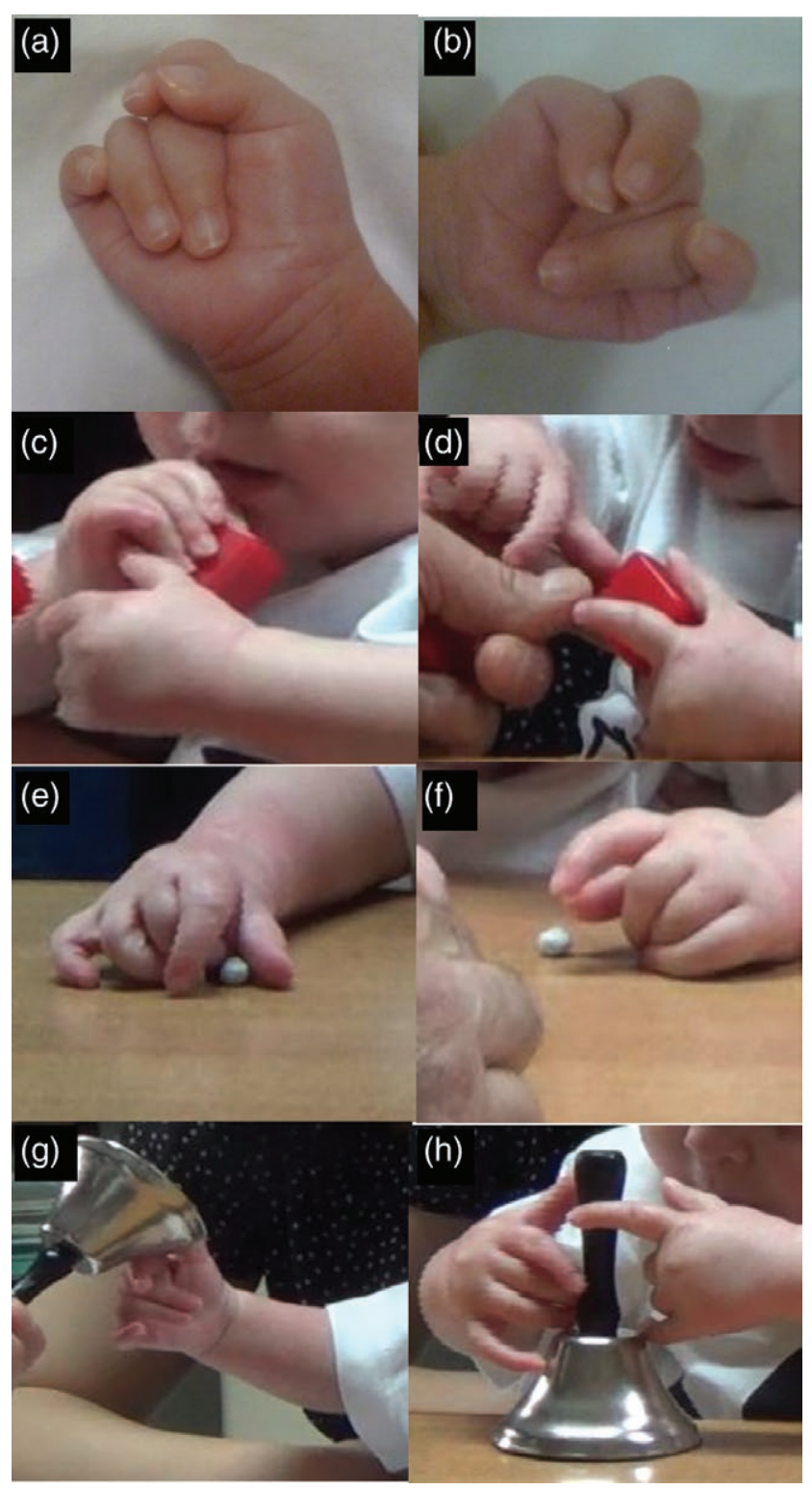

(a and b) Bilateral camptodactyly of III and IV fingers. (c and d) Use of thumb and forefinger for grasping and holding the cube. (e and $\mathrm{f}$ ) Single-pellet grasping using thumb and forefinger. ( $\mathrm{g}$ and $\mathrm{h}$ ) Manipulations and exploration of the object at 13 months.

Sohar-Crisponi syndrome/cold-induced sweating syndrome 1 (CISS1), (\#272430). The array-CGH detected a paternal deletion of $44 \mathrm{~kb}$ in a chromosome 19 [19p13.11 $\left(18,695,989 \_18,740,580\right) \times 1$ in the GRCh37 coordinates], encompassing the cytokine receptor-like factor-1 (CRLF1, \#604237), the brain-specific transmembrane protein 59-like (TMEM59L, \#617096) and the chromosome 19 open reading frame 60 (C19orf60) genes. Direct sequencing of all nine exons and exon-intron boundaries of $C R L F 1$ gene in the patient and his parents identified a
Fig. 3

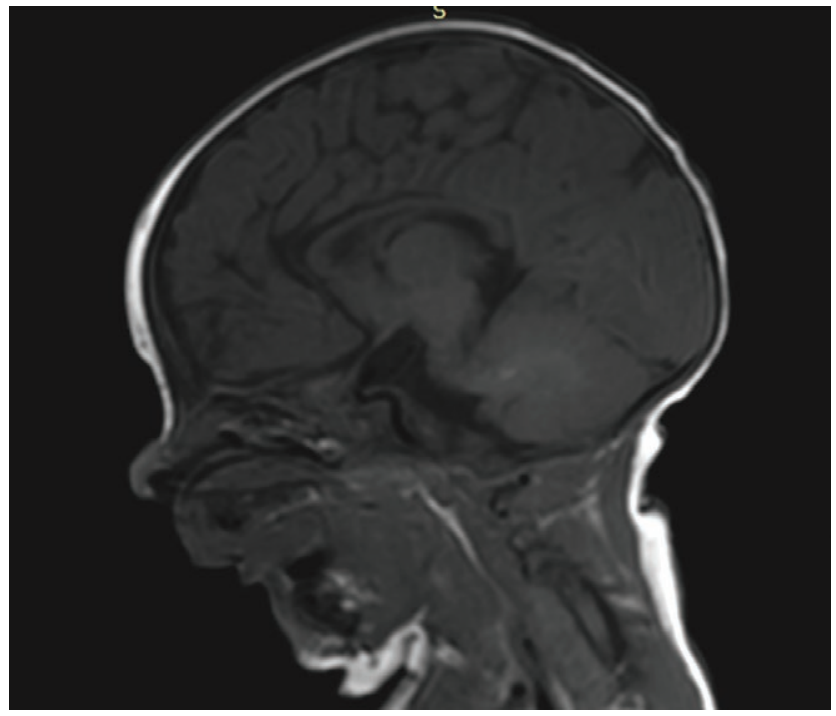

Midsagittal T2-weighted MRI of the brain shows a thin corpus callosum. Microretrognathia is an additional finding.

second maternally inherited microdeletion from intron 4 to the end of CRLF1 [NM_004750.4: c.(697+167_?) del], and specific haplotypes of polymorphic variants.

\section{Discussion}

Crisponi syndrome/CISS1, is an autosomal recessive ciliary neurotrophic factor receptor (CNTFR)-related genodermatosis caused in $95 \%$ of cases by mutations in CRLF1 on chromosome 19p13. The CNTFR pathway is important for CNS development. Crisponi syndrome/ CISS1 can be suspected in the presence of the following clinical triad: camptodactyly with fisted hands, intermittent hyperthermia and muscular contractions with feeding difficulties. Considering the overlapping symptoms, differential diagnosis to be made are as follows: CNTFRrelated genodermatoses affecting other receptor ligands (CLCF1, LIFR, and KLHL7), neonatal tetanus, Pierre Robin sequence, hereditary hyperekplexia, oculoauriculovertebral syndrome, Bowen-Conradi syndrome, Pena-Shokeir syndrome, Freeman-Sheldon/SheldonHall syndromes, trisomy 18, and MEVA (Crisponi, 1996; Shires and Chow, 2015).

We first report Crisponi syndrome/CISS1 in an infant due to compound heterozygosity for two CRLF1 deletion mutations: a maternal partial deletion encompassing exons 5-9 and a paternal $44 \mathrm{~kb}$ deletion involving also the neighboring genes TMEM59L and C19orf60. Although these two other genes have been implicated in normal neurodevelopment (Zheng et al., 2017), haploinsufficiency has not so far been reported to result in specific phenotypes. 
The relation of father's symptoms (mild feeding problems during childhood, sweating problems in adulthood) to the deletion is unclear since carrier signs are not known for CRLF1 variations (Piras et al., 2014). Another Sicilian boy with a similar clinical phenotype has been described (Di Leo et al., 2010). He was a compound heterozygote for a smaller deletion mutation of $20 \mathrm{~kb}$ encompassing exons 6-9 of the CRLF1 and C19orf60 and the missense point mutation c. $935 \mathrm{G}>\mathrm{A}$.

So far, large deletions account for about $11 \%$ of total variations and usually occurred in a homozygous condition or in compound heterozygosity with missense mutations (Piras et al., 2014).

Whilst deletions of a similar size have not been reported previously, the possibility still remains that this may be a further founder mutation in the Sicilian population.

Small subcortical white matter lesions on MRI were reported in patients with c.31_53del23 and c.413C>T mutations (Yamazaki et al., 2010; Tüysüz et al., 2013). Thin corpus callosum (Okur et al., 2008), psychomotor delay (Piras et al., 2014) as well as neurosensorial impairment (Alesi et al., 2019) were reported. In our patient, normal polysomnography confirmed a relative sparing of brainstem functions, though the presence of stimulus provoked paroxysmal muscular contractures and autonomic dysfunction with hyperthermia suggest brainstem involvement (Della Marca et al., 2008).

\section{Acknowledgements \\ Conflicts of interest}

There are no conflicts of interest.

\section{References}

Alesi V, Dentici ML, Loddo S, Genovese S, Orlando V, Calacci C, et al. (2019). Confirmation of BRD4 haploinsufficiency role in Cornelia de Lange-like phenotype and delineation of a 19p13.12p13.11 gene contiguous syndrome. Ann Hum Genet 83:100-109.

Crisponi G (1996). Autosomal recessive disorder with muscle contractions resembling neonatal tetanus, characteristic face, camptodactyly, hyperthermia, and sudden death: a new syndrome? Am J Med Genet 62:365-371.

Della Marca G, Barone G, Vollono C, Dittoni S, Vasta I, Timpani G, et al. (2008). Central apneas in a case of Crisponi syndrome. Sleep Med 9:703-704.

Di Leo R, Nolano M, Boman H, Pierangeli G, Provitera V, Knappskog PM, et al. (2010). Central and peripheral autonomic failure in cold-induced sweating syndrome type 1. Neurology 75:1567-1569.

Okur I, Tumer L, Crisponi L, Eminoglu FT, Chiappe F, Cinaz P, et al. (2008). Crisponi syndrome: a new case with additional features and new mutation in CRLF1. Am J Med Genet A 146A:3237-3239.

Piras R, Chiappe F, Torraca IL, Buers I, Usala G, Angius A, et al. (2014). Expanding the mutational spectrum of CRLF1 in Crisponi/CISS1 syndrome. Hum Mutat 35:424-433.

Shires PM, Chow G (2015). Trismus in the paediatric population. Dev Med Child Neurol 57:339-343.

Tüysüz B, Kasapçopur O, Yalçınkaya C, Işık Haşıloğlu Z, Knappskog PM, Boman $H$ (2013). Multiple small hyperintense lesions in the subcortical white matter on cranial MR images in two Turkish brothers with cold-induced sweating syndrome caused by a novel missense mutation in the CRLF1 gene. Brain Dev 35:596-601.

Yamazaki M, Kosho T, Kawachi S, Mikoshiba M, Takahashi J, Sano R, et al. (2010). Cold-induced sweating syndrome with neonatal features of Crisponi syndrome: longitudinal observation of a patient homozygous for a CRLF1 mutation. Am J Med Genet A 152A:764-769.

Zheng Q, Zheng X, Zhang L, Luo H, Qian L, Fu X, et al. (2017). The neuron-specific protein TMEM59L mediates oxidative stress-induced cell death. Mol Neurobio/ 54:4189-4200. 


\section{AUTHOR QUERY FORM}

\section{LIPPINCOTT \\ WILLIAMS AND WILKINS}

\section{JOURNAL NAME: MCD}

ARTICLE NO: CD-D-19-00040

\section{QUERIES AND / OR REMARKS}

\begin{tabular}{|l|l|l|}
\hline QUERY NO. & Details Required & Author's Response \\
\hline Q1 & $\begin{array}{l}\text { For indexing purposes, please confirm } \\
\text { that author names have been correctly } \\
\text { identified as given names (blue) and } \\
\text { surnames (red). Color in the byline } \\
\text { will not appear on the final published } \\
\text { version. }\end{array}$ & \\
\hline Q2 & $\begin{array}{l}\text { Please provide the department name in } \\
\text { affiliation 'b'. }\end{array}$ & $\begin{array}{l}\text { Please provide the fax number of the } \\
\text { corresponding author. }\end{array}$ \\
\hline Q4 & Please define 'EEG' and 'CGH'. & \\
\hline & & \\
\hline
\end{tabular}

